\title{
British military beckons environmental researchers
}

London. The British Ministry of Defence $(\mathrm{MoD})$ is putting its people, equipment and real estate at the disposal of environmental researchers in a new initiative intended to benefit science. Researchers welcome the opportunity but are scratching their heads to understand such generosity.

When the MoD's chief scientist, Sir Ron Oxburgh, announced the initiative two weeks ago, he spoke of technological interchange and the need for the services to know about

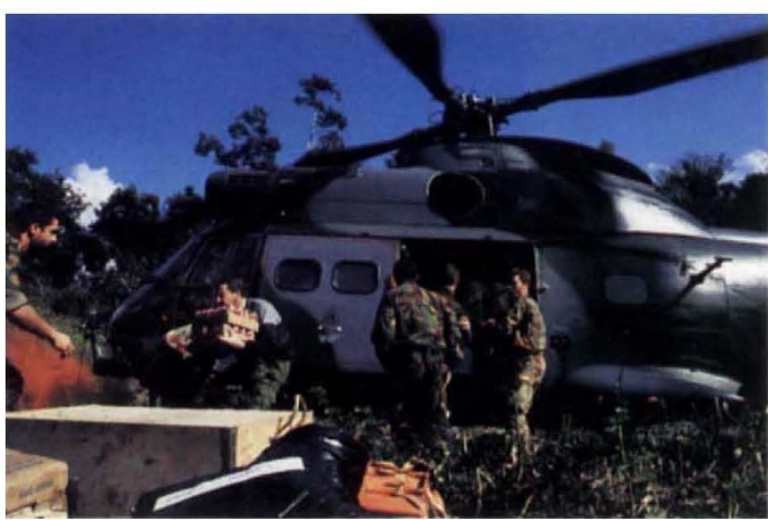

British soldlers unload supplies from a hellcopter in support of a Joint sclentific exerclse in Belize.

the environments in which they operate. But researchers who have worked with the military before suggest that the explanation may be as simple as satisfying the wishes of senior officers who like science.

The project, called Joining Forces for the Environment, is being undertaken with the Natural Environment Research Council. It provides a formal structure under which researchers can apply to work at sites on MoD land or ask the military for help in carrying out scientific projects. Although it applies to any of the sciences, the chief beneficiaries are expected to be environmental researchers and ecologists.

David Sutton, a botanist at the Natural History Museum, London, involved in coordinating the scientific element of a military training exercise to Belize in the Yucatan Peninsula of Central America, has been impressed with the commitment and expertise in the services. "There are a lot of skills that service people have that are useful to scientists - in logistics, communications and navigation", Sutton says.

The Belize expedition, which took place in January and February 1991, made a study of the botany, ecology, zoology and soil science of the upper reaches of the Raspaculo River. This area had never been visited for scientific purposes and was inaccessible before the armed forces arrived. More surprising to Sutton was the military's scientific contributions. The expedition benefited from Royal Air Force officers with expertise in ornithology, a major in the Royal Marines with skills in archaeology and a member of the Royal Navy with a background in biological computation.

The information gathered was shared with the Belize department of natural resources and with the British Overseas Development Agency, and it will also be given to other neotropical research groups. A second expedition is planned.

This enthusiasm for science has already made possible, and at times even initiated, many projects. By providing a formal application procedure, the new joint effort should greatly increase the amount of research conducted.

The MoD owns more than 600,000 acres of land in Britain, including 200 or so areas that are designated sites of special scientific interest (SSSI). Some of these ecosystems are in pristine condition, and have not been ploughed, sprayed or exposed to fertilizer for many decades. The presence of the military also means that researchers can be more confident about leaving expensive monitoring equipment on these sites for long periods of time.

Researchers have had their eye on several pieces of property owned by the military. For ecologists looking for an example of chalk grassland to be included in the Ecological Change Network, a long-term environmental monitoring programme, there are several good examples on Salisbury Plain, the MoD's training ground in the south of England. Similarly, the gunnery ranges at Cape Wrath in the far north of Scotland hold great promise for ornithologists.

More important is the prospect that the military will allow its resources and personnel to be used by researchers. This means access to remote or hostile environments, allowing monitoring equipment to hitch rides on ships and planes, or using military personnel to make routine measurements.

Although the MoD cannot subsidize any projects, researchers believe that it should be relatively easy to tailor projects to fit the forces' routine operations or scheduled training activities.

Ian Mundell

\section{Giotta encounters second comet; ready for more}

Munich. Reactivated following its damaging encounter with Halley's comet in 1986, the European space probe Giotto surprised and delighted scientists last Friday in a successful encounter with the dying GriggSkjellerup comet. Passing within an estimated $200 \mathrm{~km}$ of the comet's nucleus, Giotto has not only provided important and highquality data but has also emerged unscathed and ready for a third mission before the end of the century.

Launched in 1985 and designed to end its life after meeting Halley, Giotto provided researchers with a bonus second mission at a tiny cost. Now there is the possibility of a third, as yet undefined, encounter, making the ECU145-million (US\$190 million) space probe particularly good value for money.

The probe is no longer operating at full strength. Two of its ten scientific instruments - the neutral mass spectrometer and the particle impact analyser- and parts of the probe's extensive protective shield were destroyed in the Halley fly-by. The optical path of the camera was also blocked when hit by particles, although not before the camera had recorded the first pictures ever seen of a comet nucleus. After Giotto left Halley, scientists at the mission control centre in Darmstadt, Germany, pointed the probe towards the Earth before 'switching it off' for four years.

In February 1990, Giotto was reactivated, at a cost of ECU12 million, and aimed at its second target, a comet named for its two co-discoverers, New Zealander John Grigg and Australian John Francis Skjellerup. The comet is often upset by the gravitational pull of Jupiter, and the previous such disturbance, in 1964, pulled it just inside the Earth's orbit and within reach of Giotto. Unlike the fresh and active Halley, Grigg-Skellerup is eroded and barely active, providing an interesting contrast for studies of the common origin of comets.

Last week's experiments concentrated on plasma physics, and preliminary results contain some surprises. For example, the 'bow shock' - the shock front that precedes a comet - was much stronger than expected, and was measurable at a much greater distance, around $16,000 \mathrm{~km}$, than predicted. Magnetic wave phenomena around the comet were also unexpected, although they were textbook clear, according to Gerhard Schwehm, project scientist of the Giotto Extended Mission.

A third mission is now being discussed for 1999, and manoeuvres to set Giotto on its path back towards Earth have been delayed by a few weeks to conserve fuel.

Alison Abbott 